\title{
ON INEQUALITIES FOR POLYNOMIALS IN TWO VARIABLES
}

\author{
O. R. Gabrielyan, H. G. GhaZaryan And V. N. Margaryan
}

Abstract. Necessary and sufficient conditions are established for the comparison of the powers of polynomials in two variables with real coefficients.

Mathematics subject classification (2000): 35P15, 35J25, 47A75, 47B25.

Keywords and phrases: polynomial, power, comparison.

\section{REFERENCES}

[1] L. HöRmander, The Analysis of Linear Partial Differential Operators, Springer-Verlag, 1983.

[2] O. V. Besov, V. P. IL'In, S. M. NiKOLSKII, Integral Representations of Functions and Embedding Theorems, New York, John Wiley and Sons, v.1 (1978), v.2 (1979).

[3] L. GöRdIng, Linear Hyperbolic Partial Differential Equations, Acta Math. 85 (1951), 1-62.

[4] S. M. NiKOLSKII, The First Boundary Problem for a General Linear Equation, Soviet Math. Dokl., v.3 (1962). 1388-1390.

[5] V. I. Burenkov, On the Connection Between the Behaviour of a Solution of a Partial Differential Equation at Infinity and its Differential Properties, Proc. Steklov Inst. Math. 89 (1967), 56-68.

[6] V. I. BuRENKov, On the Effect of the Decay at Infinity of Solutions of Partial Differential Equations on their Differential Properties. Embedding Theorems and their Applications, "Nauka", Moscow (1970), 30-46. (Russian).

[7] V. P. MiKHAILOV, On the Behaviour at Infinity of a class of Polynomials, Proc. Steklov Inst. Math. 91 (1967), 59-80.

[8] B. PINI, Osservazoni Sulla Ipoelliticita, Boll. Un. Mat. Ital. 18(1963), 420-432.

[9] L. Cattabriga, Su Una Classe di Polinomi Ipoelliticita, Red. Sem. Mat. Univ. Padova 36 (1966), 285-309.

[10] J. FriBerg, Multi-quasielliptic Polynomials, Ann. Schola Norm. Sup. Pisa (3), 21 (1967), 239-260.

[11] L. R. Volevič, S. G. Gindikin, On a Class of Hypoelliptic Polynomials, Math. USSR Sb. 4 (1968), 369-384.

[12] E. PehKonen, Ein Hypoelliptisches Dirichletproblem, Comm. Math. Phys. 48, n. 3 (1978), 131-143.

[13] G. G. KazArian, V. N. Margaryan, Criteria for Hypoellipticity in Terms of Power and Strength of Operators Proc. Steklov Inst. Math. v. 150 Issue 4 (1981), 135-150.

[14] H. G. Ghazaryan, V. N. Margaryan, Behaviour at Infinity of the Polynomials of Two Variables. Topics in Analysis and its Applications, NATO Science Series, "Kluver", London, 2004, 163-190.

[15] G. G. KAZARIAN, Comparison of Differential Operators and Differential Operators of Constant Strength, Soviet Math. Dokl. 14 (1974), 249-253.

[16] H. G. KazARIAn, The Addition of Lowest Terms of Differential Polynomials, Izv. Akad. Nauk Arm. SSR, Math., v. 9, (1974), 473-485.

[17] H. G. GhaZaryan, V. N. Margaryan, On the Behavior of Non-elliptic Polynomials $P\left(\xi_{1}, \xi_{2}\right)$ at Infinity, Izv. Nat Akad. Nauk Armenii. Mat. v. 39, n.3, (2004), 1-18. 